\title{
Practical Issues of Inhibition in Forensic Body Fluid Identifications
}

\author{
Jun Ohta* \\ Department of Forensic Biology, Scientific Crime Laboratory, Kanagawa Prefectural Police, Japan
}

*Corresponding author: Jun Ohta, Department of Forensic Biology, Scientific Crime Laboratory, Kanagawa Prefectural Police, 155-1, Yamashita-cho, Naka-ku, Yokohama, Kanagawa 231-0023, Japan

Submission: 海 September 27, 2017; Published: 海 October 23, 2017

\begin{abstract}
Factors that inhibit the analysis of bodily fluids can result in inaccurate determinations by forensics experts. This paper points out the issues with the current practical tests focused on contamination of forensic samples and inhibition of testing. Several previous studies have shown that there are inhibitory substances that prevent the accurate identification of blood, saliva, and semen. Although these bodily fluids are important sources of evidence in criminal investigations, practical measures have not been established to eliminate the inhibition of accurate results. Thus, further studies focusing on the inhibition issues are necessary to resolve the actual issues.
\end{abstract}

Keywords: Forensic biology; Body fluid identification; Inhibition; Blood; Saliva; Semen

\section{Introduction}

The main objectives of forensic biological examinations are body fluid analysis and identification of persons involved in a criminal act. Recent molecular biological techniques have enabled the analysis of trace and impure forensic samples. In particular, polymerase chain reaction (PCR)-based DNA typing is the standard test used in human identification worldwide [1]. PCR technology is suitable for analysis of trace particles of evidence; however, the problem with PCR inhibition is known for making proper amplification difficult. Several previous studies have presented

\section{Case Studies}

\section{Blood identification}

Table 1: Inhibitors of body fluid identification.

\begin{tabular}{|c|c|c|c|c|c|}
\hline Body Fluid & Method & Target & Mechanism & Inhibitor & Reference \\
\hline \multirow{2}{*}{ Blood } & Leucomalachite green test & Hemoglobin (Heme) & $\begin{array}{l}\text { Oxidation-reduction } \\
\text { reaction }\end{array}$ & Vitamin C & {$[6,7]$} \\
\hline & $\begin{array}{c}\text { Immunochromatographic } \\
\text { test }\end{array}$ & Hemoglobin & $\begin{array}{l}\text { Antigen-antibody } \\
\text { reaction }\end{array}$ & Methamphetamine & [8] \\
\hline Saliva & Amylase test & Salivary $\alpha$-amylase & Enzyme reaction & $\mathrm{Fe}^{3+}$ ion, Citric acid & [9] \\
\hline Semen & Acid phosphatase test & $\begin{array}{l}\text { Prostatic acid } \\
\text { phosphatase }\end{array}$ & Enzyme reaction & Detergent & {$[6]$} \\
\hline
\end{tabular}

To determine the presence of human blood from evidence, presumptive tests (e.g., leucomalachite green) and immunochromatographic tests (e.g., RSID ${ }^{\mathrm{TM}}$-Blood) are generally applied. Previous studies have reported that vitamin $\mathrm{C}$ and the liquids that contain the vitamin are strong inhibitors of the leucomalachite green reaction [6,7] (Table 1). This countermeasures for PCR inhibition, and many have been applied to forensic caseworks [2-5]; however, the issue of inhibition is crucial not only for human identification by PCR-based DNA typing but also for the identification of bodily fluids using various techniques. Despite the fact that identifying the source of DNA profiles contributes to the criminal investigation as well as to personal individualization, there are few studies that focus on the inhibition issue surrounding the identification of bodily fluids. This paper describes current challenges of inhibition using several examples that could be problematic in forensic casework. 
results in immunochromatography using human hemoglobin A as an indicator [8]. Although both of these examples are serious issues in casework, practical countermeasures against them have not been established.

\section{Saliva identification}

Catalytic reactions (e.g., Phadebas ${ }^{\circledR}$ ) that are focused on salivary $\alpha$-amylase activity are the prevailing tests for saliva screening. Our research suggested that $\mathrm{Fe}^{3+}$ ion, blood, citric acid, and the beverages containing citric acid inhibit the enzyme's activity in various ways [9]. As the results of quantitative analysis using absorbance measurements, these substances inhibited the enzyme reaction enough to induce false-negative results. These inhibitors that are present in the crime scene environment might mix with saliva samples taken at the scene. Thus, our inhibitor-resistant testing might be useful in searching for saliva that is colorless and contaminated from the environment; however, further studies are required to apply the method for casework analysis because there are limitations to this approach depending on the types and amounts of inhibitors.

\section{Semen identification}

Before microscopic testing to identify semen, sexual assault samples were examined using acid phosphatase (AP) tests. Because AP tests are dependent on prostatic AP activity in semen, inhibition might occur when the sample is contaminated with enzymatic inhibitors. Vennemann et al. [6] indicated that the results of AP testing in the presence of detergent showed marked enzyme inhibition. They confirmed reducing of positive results from detergent mixed semen stains using a general qualitative AP test. On the contrary, it has long been known that AP derived from the human prostate has a certain molecular property that is inhibited by L-tartrate [10]. This property might also be an unexpected inhibitory factor

\section{Discussion}

It is inevitable that forensic biological samples will contain inhibitory substances derived from the environment; therefore, identification of and countermeasures to prevent inhibitors are necessary for valid sample testing. Various types of inhibition can also occur due to the various molecular biological techniques that are used to identify the bodily fluids. Table 1 presents examples of inhibitory factors when identifying blood, saliva, and semen. Because these bodily fluids are major sources of DNA in crime investigations, forensic examiners occasionally must deal with inhibition issues. As described, previous studies on inhibition are not sufficient to resolve practical issues. In addition, the inhibitors introduced in this article might also affect the identification of different bodily fluids. For example, detergents can affect AP test as well as many other tests based on enzymatic reactions and compounds that affect the structure and function of proteins might influence testing, such as direct PCR performed without purification. Additional studies that focus on the factors that inhibit the identification of bodily fluids are needed. These studies should present countermeasures against these inhibitors, such as methods to purify samples, methods of applying resistant testing, and methods for alternative testing. Several alternative approaches (e.g., enzyme-linked immunosorbent assay, PCR, mass spectrometry) have been studied for identifying the bodily fluids used in forensics [8,11-14]; however, these methods are not widely used in casework because they are not as convenient or cost effective as conventional presumptive tests. The key point is that when dealing with samples that are suspected to be contaminated and inhibited, the samples should be evaluated using multiple tests when possible.

\section{Conclusions}

Because it is inevitable that unknown inhibitors may be mixed in forensic samples, identification of bodily fluids from impure samples should be evaluated by multiple tests. Further studies are required to identify inhibitors for each test; otherwise, forensic experts cannot aware the influence of inhibition in actual casework.

\section{References}

1. Butler JM (2005) Forensic DNA Typing, (2nd edn), Academic Press, USA.

2. Hu Q, Liu Y, Yi S, Huang D (2015) A comparison of four methods for PCR inhibitor removal. Forensic Sci Int Genet 16: 94-97.

3. Thompson RE, Duncan G, McCord BR (2014) An investigation of PCR inhibition using Plexor( $(\circledR)$-based quantitative PCR and short tandem repeat amplification. J Forensic Sci 59(6): 1517-1529.

4. Faber KL, Person EC, Hudlow WR (2013) PCR inhibitor removal using the NucleoSpin ${ }^{\circledR}$ DNA Clean-Up XS kit. Forensic Sci Int Genet 7(1): 209213.

5. Alaeddini R (2012) Forensic implications of PCR inhibition-A review. Forensic Sci Int Genet 6(3): 297-305.

6. Vennemann M, Scott G, Curran L, Bittner F, Tobe SS (2014) Sensitivity and specificity of presumptive tests for blood, saliva and semen. Forensic Sci Med Pathol 10(1): 69-75.

7. Lee H, Park MJ, Sun SH, Choi DH, Lee YH, et al. (2016) Ascorbic acid and vitamin C-containing beverages delay the leucomalachite green reaction to detect latent bloodstains. Leg Med (Tokyo) 23: 79-85.

8. Matsumura S, Matsusue A, Waters B, Kashiwagi M, Hara K, et al. (2016) Application of mRNA Expression Analysis to Human Blood Identification in Degenerated Samples that were False-negative by Immunochromatography. J Forensic Sci 61(4): 903-912.

9. Ohta J, Ohmura M (2017) Reducing of salivary $\alpha$-amylase inhibition by using bovine serum albumin and calcium chloride for forensic saliva screening. Leg Med (Tokyo) 28: 54-58.

10.Tamaki K, Fujisawa K, Okajima H, Sato K, Katsumata Y (1989) Identification of semen in stain by determination of the specific activity of L-tartrate-inhibitable acid phosphatase. Z Rechtsmed 102(7): 429436.

11.Akutsu T, Watanabe K, Fujinami Y, Sakurada K (2010) Applicability of ELISA detection of statherin for forensic identification of saliva. Int J Legal Med 124(5): 493-498.

12.Sakurada K, Ikegaya H, Fukushima H, Akutsu T, Watanabe K (2009) Evaluation of mRNA-based approach for identification of saliva and semen. Leg Med (Tokyo) 11(3): 125-128.

13. Choi A, Shin KJ, Yang WI, Lee HY (2014) Body fluid identification by integrated analysis of DNA methylation and body fluid-specific microbial DNA. Int J Legal Med 128(1): 33-41.

14.Van SK, De Ceuleneer M, Dhaenens M, Van Hoofstat D, Deforce D (2013) Mass spectrometry-based proteomics as a tool to identify biological matrices in forensic science. Int J Legal Med 127(2): 287-298. 